\title{
Time-Varying Hydraulic Gradient Model of Paste-Like Tailings in Long-Distance Pipeline Transportation
}

\author{
Li Yang, Shuai Li, and Xin-min Wang \\ School of Resources and Safety Engineering, Central South University, Changsha 410083, China \\ Correspondence should be addressed to Shuai Li; 15200826420@163.com
}

Received 24 May 2017; Accepted 24 July 2017; Published 23 August 2017

Academic Editor: Marco Cannas

Copyright (C) 2017 Li Yang et al. This is an open access article distributed under the Creative Commons Attribution License, which permits unrestricted use, distribution, and reproduction in any medium, provided the original work is properly cited.

\begin{abstract}
Paste-like tailings slurry (PTLS) is always simplified as a Bingham plastic fluid, leading to excessive computational errors in the calculation of the hydraulic gradient. In the case of paste-like tailings in long-distance pipeline transportation, to explore a highprecision and reliable hydraulic gradient formula, the rheological behavior of paste-like tailings slurry was analyzed, a time-varying hydraulic gradient model was constructed, and a series of laboratory shear tests were conducted. The results indicate that the PTLS shows noticeable shear-thinning characteristics in constant shear tests; the calculated hydraulic gradient declined by about $56 \%$, from $4.44 \mathrm{MPa} \cdot \mathrm{km}^{-1}$ to $1.95 \mathrm{MPa} \cdot \mathrm{km}^{-1}$ within $253 \mathrm{~s}$, and remained constant for the next four hours during the pipeline transportation. Comparing with the balance hydraulic gradient obtained in a semi-industrial loop test, the computational errors of those calculated by using the time-varying hydraulic gradient model, Jinchuan formula, and Shanxi formula are $15 \%, 78 \%$, and $130 \%$, respectively. Therefore, our model is a feasible and high-precision solution for the calculation of the hydraulic gradient of paste-like tailings in long-distance pipeline transportation.
\end{abstract}

\section{Introduction}

In the last twenty years, paste technology has been widely accepted as an environment-friendly, economical, and effective way in tailings disposal and stope backfilling [1]. Paste is dewatered tailings with little or no water bleed, which is nonsegregating in nature (Figure 1). It can be disposed on the surface with less chance of failure, lower seepage probability, and a smaller impact scope compared to a conventional impoundment $[2,3]$.

Table 1 summarizes several typical examples of paste tailings disposal mines in the world [4]. Evidently, many mines' tailings are actually disposed as "paste-like" rather than as designed paste tailings. The primary reason is that tailings are finely ground before mineral extraction, resulting in the tailings slurry being abundant in slow-settling particles such as electronegative slimes, ultrafine tailings, and beneficiation reagents [5]. Therefore, it is difficult to achieve a paste level with an underflow concentration that varies with the tailings' sizes and properties [6].

In previous studies, paste-like tailings slurry (PLTS) was simplified as a Bingham plastic fluid, whose flow properties were time-independent, and the existing empirical formulas for calculating the hydraulic gradient of a paste-like flow were derived based on the time-invariant Bingham model [7]. However, an increasing number of studies have shown that the rheological characteristics of PLTS are consistent with those of a pseudo-plastic fluid, and the existing empirical formulas are optimal for calculating the error and for small applications [8]. Pornillos [9] found that the yield stress of thickened tailings slurry showed distinct time-varying behavior under a continuous shear stress. Senapati and Mishra [10] evaluated the head loss of paste-like coal combustion slurry using the power-law-fluid-based head loss model and got results with a higher precision than that with empirical formulas. Li et al. [11] calculated the hydraulic gradient of cemented paste-like backfill in long pipeline transportation and found that the design error reached as high as $40 \%$ using empirical formulas. Therefore, avoiding the simplification of PLTS as a Bingham plastic fluid and deriving a time-varying hydraulic gradient model for PLTS is of great significance.

This paper discusses the disposal of paste-like tailings in the largest underground iron mine in Asia and presents the time-varying behavior of PLTS by employing groups of shear 
TABLE 1: Application examples of paste tailings disposal mines.

\begin{tabular}{lccc}
\hline Mines name and locations & Application environment & Tailings concentration & Capacity (t/d) \\
\hline Jinshandian Iron Mine, Hubei, China & Southern rainy regions & $62 \%$ (Paste-like) & 4000 \\
Wushan Cu-Mo Mine, Inner Mongolia, China & Arid and cold regions & $65 \%$ (Paste-like) & 30000 \\
Musselwhite Mine, Ontario, Canada & Cold and flat regions & $65 \%$ (Paste-like) \\
Toromocho Mine, Junin, Peru & Arid and high earthquake intensity zone & $67 \%($ Paste-like) & 4000 \\
Esperanza Mine, Coquimbo, Chile & Arid and high earthquake intensity zone & $69 \%($ Paste) & 117000 \\
Garpenberg Mine, Stockholm, Sweden & Cold regions & $70 \%($ Paste) & - \\
\hline
\end{tabular}

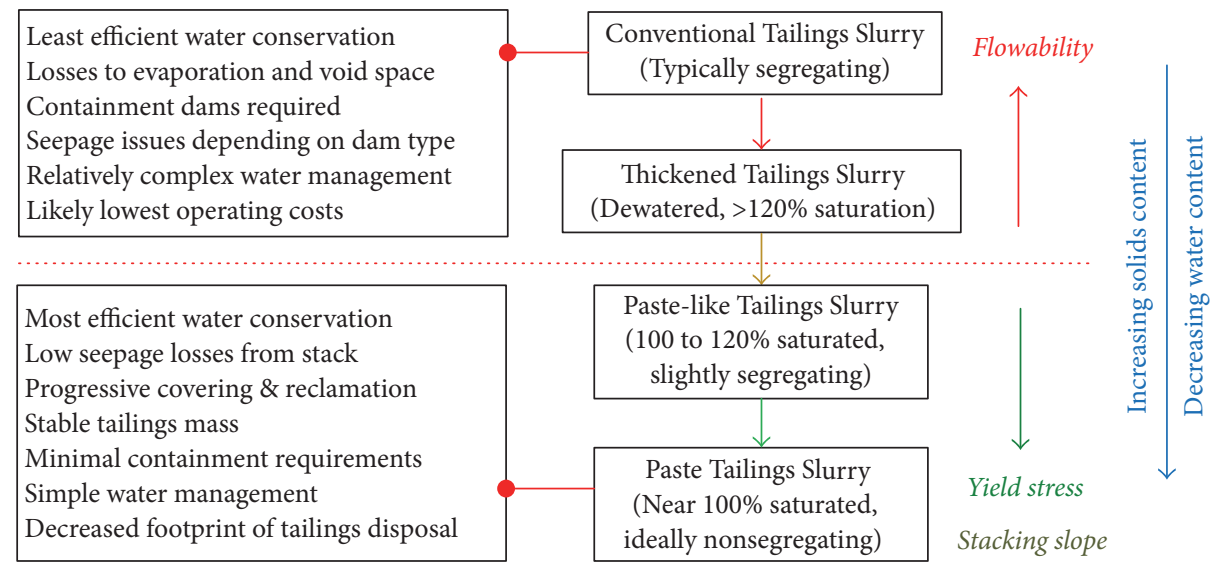

FIGURE 1: Comparison of different tailings surface disposal methods.

tests. A time-varying hydraulic gradient model of PLTS in long-distance pipeline transportation was derived based on the theory of flocculent structure and the Herschel-Bulkley model. The reliability of the time-varying hydraulic gradient model was analyzed and compared with a semi-industrial loop test and conventional semiempirical formulas.

\section{Flocculent Structures (FS) and Rheological Model of PLTS}

2.1. Preparation of PLTS. The Sijiaying Iron Mine in Hebei, China, successfully commissioned in 2007, is the largest underground iron mine in Asia to adopt a total paste-like solution for all of its tailings. About 40 million tons/year of argillized ultrafine tailings slurry will be used for stopes backfilling, and the remainder will be "stacked" on the surface. Figure 2 presents a flow chart of the preparation and transportation of PLTS in Sijiaying.

As part of a widely accepted practice, efficient tailingsthickening equipment, such as deep-cone thickeners with a diameter of $25 \mathrm{~m}$, is used in Sijiaying to obtain PLTS. After being uniformly mixed with flocculants, the sedimentation of argillized ultrafine tailings is accelerated, and the tailings concentration can be improved to $65 \%$. With a solids content less than $300 \mathrm{ppm}$, the overflow water can be reused for flotation [12]. The tailings disposal storage, which is located in the subsidence of the Fangezhuang Coal Mine, is $30 \mathrm{~km}$ from Sijiaying. The paste-like underflow is transported by using piston pumps in a long-distance pipeline and then dumped and evaporated. There are several benefits cited by
Sijiaying in their decision to develop the paste-like tailings disposal system: improving the dam safety in floods and earthquakes, water recycling, and decreasing the footprint of tailings disposal sites [13].

2.2. FS of PLTS. The tailings slurry in the highly oxidized and argillized hematite mine of Sijiaying is abundant in electronegative slimes and ultrafine tailings. The cationic polyacrylamide (CPAM) with a molecular weight of 18 million exhibited good flocculation and sedimentation after a series of flocculant selection tests. Charge neutralization and bridging constitute the main mechanisms of CPAM [14]. The negatively charged slimes and tailings are neutralized by cations after the CPAM is uniformly mixed, which weakens the strong repulsive interactions of the tailings. Consequently, the thick hydration shells get thinner. The long molecular chains from CPAM will release linearly structured reactive groups after the process of hydrolysis and polycondensation; they then experience mutual attraction by the formation of multiple colloidal bonds, capturing and gathering through bridging, and finally developing into FS [15]. FS, which are unstable, can not only be stretched or damaged by mechanical mixing, but also lapped or recombined by bridging (Figure 3) [16].

This dynamic damage and recovery process of FS can be described as

$$
\frac{\mathrm{d} S}{\mathrm{~d} t}=k_{1}(1-S)-k_{2} S \dot{\gamma}
$$




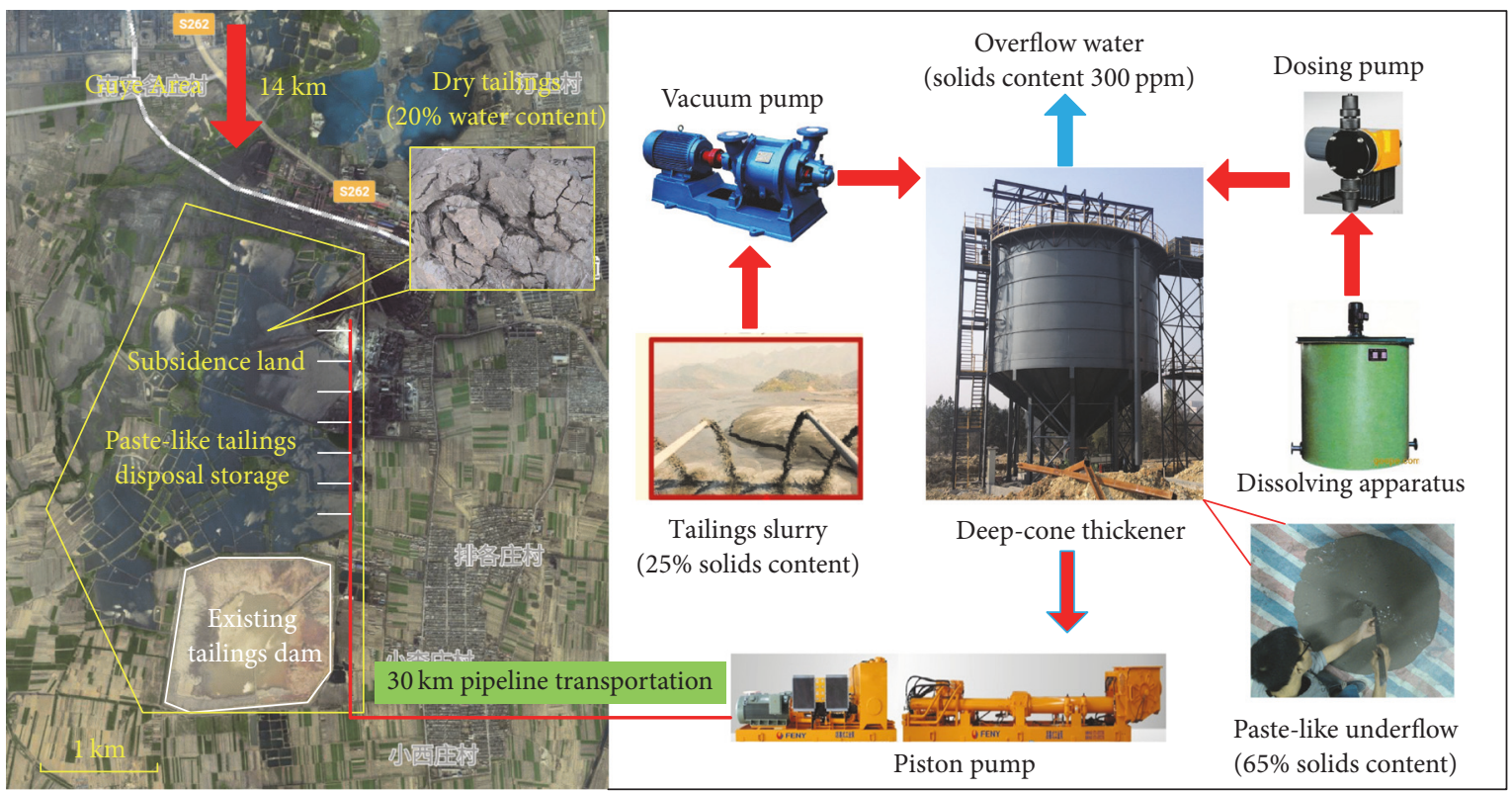

FIGURE 2: The preparation and transportation of PLTS in Sijiaying.

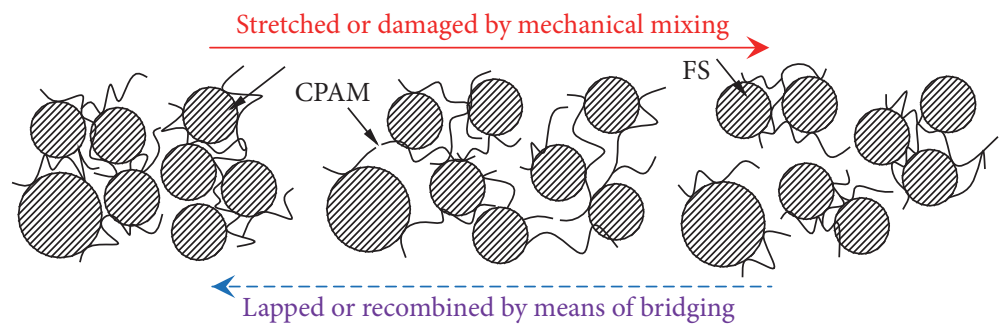

FIGURE 3: The dynamic damage and recovery process of FS.

where $S$ is the FS coefficient, reflecting the degree of integrity of FS; $\mathbf{r}$ is shear rate expressed in $\mathrm{s}^{-1} ; k_{1}$ is the recovery coefficient, which depends on the flocculant dosage; and $k_{2}$ is the damage coefficient, directly proportional to $\mathbf{r} . S=0$ is defined as the stage where the FS are completely destroyed, while $S=1$ is the stage where the FS are fully developed. When $(1)=0$, it means that the damage and recovery processes have reached a dynamic balance, and the FS balance coefficient $S_{0}$ can be obtained as

$$
S_{0}=\frac{k_{1}}{\left(k_{1}+k_{2} \dot{\gamma}\right)} \text {. }
$$

After integrating (1), the following equation can be obtained:

$$
S=\frac{k_{1}+k_{2} \dot{\gamma} \mathrm{e}^{-\left(k_{1}+k_{2} \dot{\gamma}\right) t}}{k_{1}+k_{2} \dot{\gamma}}=S_{0}+\frac{k_{2} \dot{\gamma}}{k_{1}+k_{2} \dot{\gamma}} \mathrm{e}^{-\left(k_{1}+k_{2} \dot{\gamma}\right) t} .
$$

2.3. Rheological Model of PLTS. Non-Newtonian fluids include Bingham plastic fluid, pseudo-plastic fluid, and expansion fluid, depending on different rheological properties [17]. To validate the rheological model of PLTS, shear stresses with different shear rates were tested. The results show that the behavior of PLTS is consistent with that of a pseudo-plastic fluid, and the Herschel-Bulkley model is more applicable to PLTS. The constitutive equation of the Herschel-Bulkley model is commonly written as

$$
\tau=\tau_{0}+\eta \dot{\gamma}^{n}
$$

where $\tau$ is the shear stress in $\mathrm{Pa} ; \tau_{0}$ is the yield stress in $\mathrm{Pa} ; \eta$ is the apparent viscosity in Pa.s; and $n$ is the flow index, $n<1$.

As shown in (3), the FS show noticeable shear-thinning characteristics under a particular shear rate, as $S$ decreases gradually with the increase in shear time and finally reaches the balanced value $S_{0}$. The time-varying behavior of PLTS can be further manifested in the change laws between the parameters of the Herschel-Bulkley model and $S$, which is reflected in the mathematical model given by

$$
\begin{aligned}
\tau_{0} & =S \tau_{1}, \\
\eta & =\eta_{\infty}+S k_{3}, \\
n & =S n_{0},
\end{aligned}
$$


TABLE 2: Main tailings properties of Sijiaying.

\begin{tabular}{lccccccc}
\hline $\begin{array}{l}\text { Properties } \\
\text { indexes }\end{array}$ & $\begin{array}{c}\mathrm{pH} \\
\text { value }\end{array}$ & Porosity $/ \%$ & $\begin{array}{c}\text { Bulk } \\
\text { density } / \mathrm{t} \cdot \mathrm{m}^{-3}\end{array}$ & Density $/ \mathrm{t} \cdot \mathrm{m}^{-3}$ & $\begin{array}{c}\text { Average } \\
\text { size } / \mu \mathrm{m}\end{array}$ & $\begin{array}{c}\text { Content of } \\
<37 \mu \mathrm{m} / \%\end{array}$ & $\begin{array}{c}\text { Content of } \\
>74 \mu \mathrm{m} / \%\end{array}$ \\
\hline Value & $7-8$ & 55.66 & 1.40 & 3.09 & 19 & 70.02 & 8.9 \\
\hline
\end{tabular}

where $\tau_{1}$ and $n_{0}$ are the initial yield stress and initial flow index, respectively; $\eta_{\infty}$ is the apparent viscosity when the FS are completely destroyed; and $k_{3}$ is the viscosity coefficient of the FS. The rheological model of PLTS based on the flocculent structure theory can be obtained by integrating (4) and (5):

$$
\begin{aligned}
\tau & =S \tau_{1}+\left(\eta_{\infty}+S k_{3}\right) \gamma^{S n_{0}} \\
& =f\left(\tau_{1}, \eta_{\infty}, n_{0}, k_{1}, k_{2}, k_{3}, \dot{\gamma}, t\right) .
\end{aligned}
$$

2.4. Time-Varying Hydraulic Gradient Model of PLTS. The hydraulic gradient, or resistance loss, is the most important parameter in long-distance pipeline transportation, affecting the operation consumption and reliable operation of a PLTS disposal system. In the present study, the hydraulic gradient formula of PLTS was derived based on the time-invariant Bingham model:

$$
i_{0}=\frac{16}{3 D} \tau_{0}+\frac{32 v}{D^{2}} \eta
$$

where $i_{0}$ is the hydraulic gradient in $\mathrm{Pa} / \mathrm{m} ; D$ is the pipe diameter in $\mathrm{m}$; and $v$ is the average flow velocity in $\mathrm{m} / \mathrm{s}$.

There is usually a long pipe-feeding distance before the PLTS arrives at the storage, and the continuous shearing force provided by the pipe wall can last several hours. Under the action of a continuous shearing force, the PLTS clearly shows time-varying behavior, resulting in a large error in the hydraulic gradient calculation. Therefore, the hydraulic gradient formula of PLTS should be modified by using the timevarying flocculent structure theory and the Herschel-Bulkley model. The time-varying hydraulic gradient model of PLTS can then be obtained by integrating (3), (5), and (7):

$$
\begin{aligned}
\tau_{0}=S \tau_{1}=S_{0} \tau_{1}+a \mathrm{e}^{-\left(k_{1}+k_{2} \dot{\gamma}\right) t}, \quad a=\frac{\tau_{1} k_{2} \dot{\gamma}}{\left(k_{1}+k_{2} \dot{\gamma}\right)} & \\
\eta= & \eta_{\infty}+S k_{3}=\eta_{\infty}+S_{0} k_{3}+b \mathrm{e}^{-\left(k_{1}+k_{2} \dot{\gamma}\right) t}, \\
i_{0}= & \frac{16}{3 D} S_{0} \tau_{1}+\frac{32 v}{D^{2}}\left(\eta_{\infty}+S_{0} k_{3}\right) \\
& +\left(\frac{16}{3 D} a+\frac{32 v}{D^{2}} b\right) \mathrm{e}^{-\left(k_{1}+k_{2} \dot{\gamma}\right) t},
\end{aligned}
$$

where $a$ and $b$ are dimensionless parameters in the simplified formula.

From (8), it can be seen that the modified $\tau_{0}, \eta$, and $i_{0}$ of the PLTS are all decreasing functions of time. Under the action of a continuous shearing force, the FS are destroyed gradually, resulting in a decline in the rheological properties.
TABLE 3: Particle sizes of slow-settling particles.

\begin{tabular}{lccccc}
\hline$D / \mu \mathrm{m}$ & $D<6.5$ & $18>D>6.5$ & $26>D>18$ & $36>D>26$ & $D>36$ \\
\hline Content/\% & 71.20 & 15.15 & 5.20 & 3.05 & 5.40 \\
\hline
\end{tabular}

\section{Laboratory Shear Tests}

3.1. Properties of Tailings. The properties of the tailings and the particle size are the most important parameters affecting the rheological model and FS of the PLTS. The properties of the tailings of Sijiaying are summarized in Table 2, where they are classified as ultrafine, with $70 \%$ of the content smaller than $37 \mu \mathrm{m}$ and $8.9 \%$ larger than $74 \mu \mathrm{m}$. As this mine is a highly oxidized and argillized hematite mine, the tailings slurry is abundant in electronegative slimes and ultrafine tailings. Since like charges repel, the strong electrostatic repulsion between the slow-settling particles causes a large flocculant dosage and a paste-like underflow from the deepcone thickener. The particle size of the slow-settling particles is denoted by $D$ (Table 3); the content less than $6.5 \mu \mathrm{m}$ in size exceeds $71 \%$, which will attract nearby polar water molecules and form thick hydration shells blocking the flocculation and sedimentation processes.

3.2. Experimental Procedure. The HAAKE VT550 rotary viscometer was used for laboratory shear tests. The immersion sensor, whose cross-shaped rotor overcomes the slip effect of the PLTS, has higher measurement accuracy than a traditional coaxial cylinder. The control software, which is installed in the computer, can easily handle and record slight changes in the rheological parameters during shear tests. The PLTS of Sijiaying with a mass concentration of $65 \%$ was prepared in advance, rapidly stirred using an electric mixer, and kept stagnant for about $5 \mathrm{~min}$. Subsequently, $900 \mathrm{~g}$ of PLTS was taken in a $500 \mathrm{~mL}$ beaker, and placed under the viscometer. The initial yield stress was defined as the shear stress when the rotor began rolling. Constant shear tests were conducted to measure the apparent viscosity and shear stress of the PLTS in five groups, with shear rates within $600 \mathrm{~s}$.

3.3. Results and Analyses. The variation in the shear stress and apparent viscosity with the shear time are shown in Figure 4. The shear rate is set as $20 \mathrm{~s}^{-1}, 30 \mathrm{~s}^{-1}, 40 \mathrm{~s}^{-1}, 50 \mathrm{~s}^{-1}$, and $60 \mathrm{~s}^{-1}$.

The PLTS of Sijiaying clearly showed shear-thinning characteristics in the constant shear tests conducted in the laboratory. When the shear time was zero, the shear stress and apparent viscosity of the PLTS had the highest values, which meant that the FS were fully developed. Under a particular shear rate, the FS of PLTS were destroyed gradually, resulting in a rapid decline in the shear stress and apparent viscosity. The balance time was defined as the time when the shear 


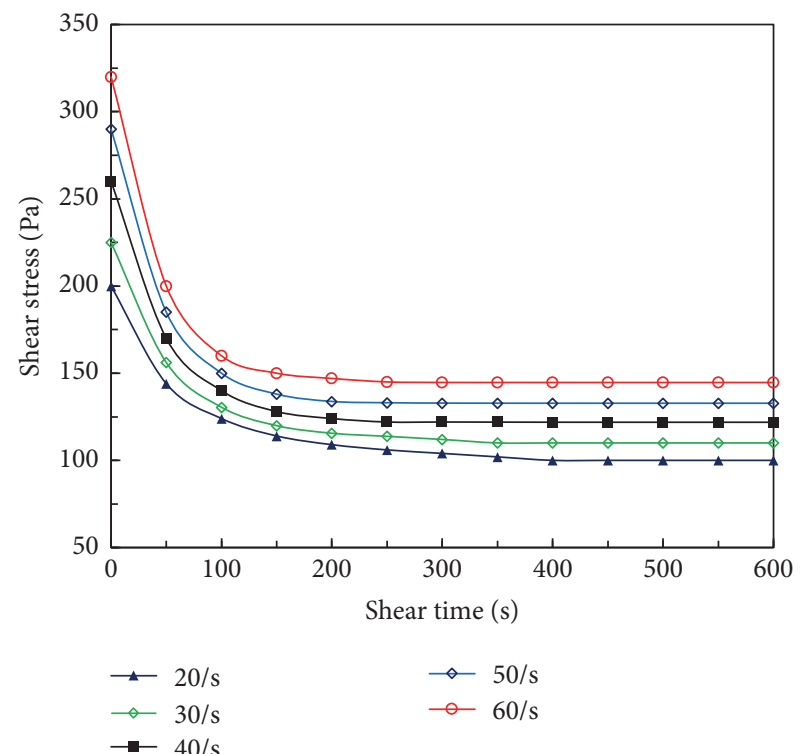

(a)

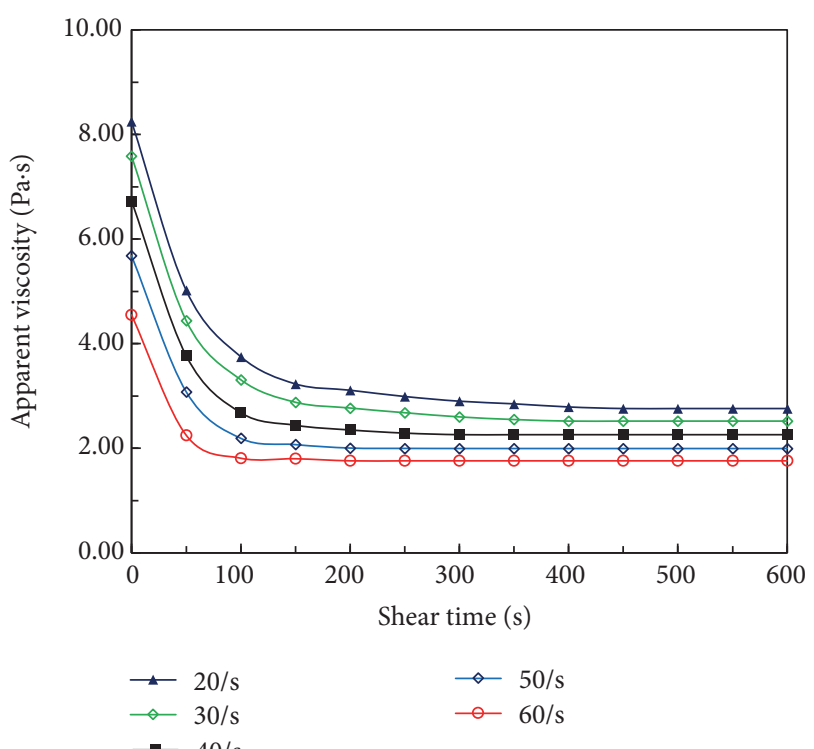

(b)

FIGURE 4: Varying tendency of rheological parameters with shear time: (a) shear stress; (b) apparent viscosity.

TABLE 4: The balance rheological parameters of PLTS.

\begin{tabular}{lccccc}
\hline Shear rate $/ \mathrm{s}^{-1}$ & 20 & 30 & 40 & 50 & 60 \\
\hline Balance apparent viscosity $\eta_{b} /(\mathrm{Pa} \cdot \mathrm{s})$ & 2.76 & 2.55 & 2.26 & 2.02 & 1.76 \\
Balance shear time $t_{b} / \mathrm{s}$ & 381 & 324 & 307 & 267 & 230 \\
Balance shear stress $\tau_{b} / \mathrm{Pa}$ & 100.2 & 111.5 & 121.9 & 132.8 & 144.7 \\
\hline
\end{tabular}

stress and apparent viscosity acquired steady values. The calculated balance times of the five groups with different shear rates were 381 s, 324 s, 307 s, 267 s, and 230 s, respectively. The damage process was accelerated with the increase in shear rate. The greater the shear rate, the shorter the balance time.

3.4. Error Analysis. All the balanced rheological parameters of the PLTS in the constant shear tests conducted in the laboratory are summarized in Table 4 . A nonlinear equation can be obtained by substituting the data in (6). After a series of arithmetic operations, an optimal solution was obtained by using the damped least-squares method:

$$
\begin{aligned}
\tau= & f\left(\tau_{1}, \eta_{\infty}, n_{0}, k_{1}, k_{2}, k_{3}, \dot{\gamma}, t\right) \\
& =f\left(118.5,1.48,0.99,6.95 \times 10^{-3}, 3.6\right. \\
& \left.\times 10^{-4}, 1.85, \dot{\gamma}, t\right) .
\end{aligned}
$$

To verify the accuracy of (9), a brief comparison of the calculated shear stress and the tested values is shown in Figure 5. With the shear rates being 20, 40, and $60 \mathrm{~s}^{-1}$, the calculated shear stresses are consistent with the tested values, implying that the rheological model of the PLTS based on the theory of flocculent structure and the Herschel-Bulkley model does have a statistical significance.

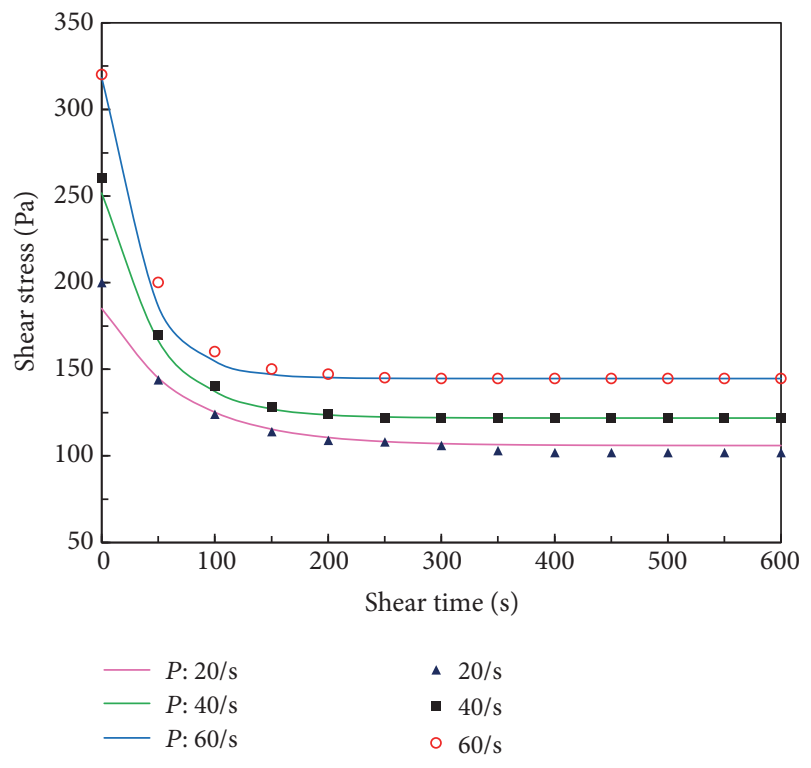

Figure 5: Comparison of the calculated shear stress and the tested values.

\section{Hydraulic Gradient Calculation and Reliability Analysis}

4.1. Hydraulic Gradient Calculation. The PLTS of Sijiaying with a mass concentration of $65 \%$ is transported by piston pumps in a $30 \mathrm{~km}$ long pipeline and then dumped and evaporated. Since the capacity of PLTS disposal is about 30 million tons/year, transporting such a large amount of PLTS in such a long-distance pipeline is proving to be particularly challenging and difficult. Therefore, an accurately calculated hydraulic gradient is especially important in reducing the 


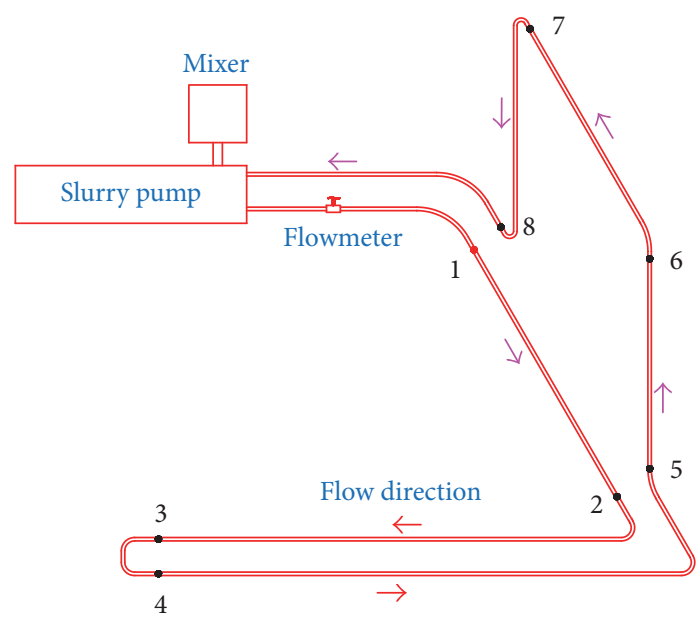

Figure 6: Layout of the loop system.

operation consumption and improving the reliability of the PLTS disposal system. The flow rate $Q$ was set to 400,450 , 500 , and $550 \mathrm{~m}^{3} \cdot \mathrm{h}^{-1}$, and the diameter of the pipeline was $300 \mathrm{~mm}$. The hydraulic gradient of the PLTS was calculated by using (8) and is given in Table 5 .

It is evident from Table 5 that the PLTS shows a timevarying behavior during the long-distance pipeline transportation, with the hydraulic gradient declining gradually and finally reaching equilibrium. When the flow rate was $500 \mathrm{~m}^{3} \cdot \mathrm{h}^{-1}$, the calculated hydraulic gradient of the PLTS declined by about $56 \%$, from $4.44 \mathrm{MPa} \cdot \mathrm{km}^{-1}$ to $1.95 \mathrm{MPa} \cdot \mathrm{km}^{-1}$ within $253 \mathrm{~s}$. With an increase in the flow rate, the balance time becomes shorter while the balance hydraulic gradient becomes larger. With an average flow velocity of $1.97 \mathrm{~m} \cdot \mathrm{s}^{-1}$, it takes approximately four hours to transport the PLTS to the storage. Therefore, it is more systematic and reasonable to use the balance hydraulic gradient for the pipeline design and pump selection. Besides, it is advisable to stir the PLTS thoroughly before transportation, to destroy the FS completely, and reduce the hydraulic gradient effectively, based on the time-varying behavior of the PLTS.

4.2. Reliability Analysis. The conventional semiempirical hydraulic gradient formulas, which were derived based on a two-phase flow laboratory date, show a limited applicable scope [18]. For example, Durand's formula may be suitable for the short-distance transportation of coarse and lowconcentration crude tailings. As a widely accepted formula in China, the Shanxi Shuiliyuan formula is suitable for coarse particles, and the Jinchuan formula gives a high precision in calculations related to high-concentration rod-milling sand [19].

To evaluate the reliability of the calculated hydraulic gradient by using (8), a semi-industrial loop test was conducted. The hydraulic gradients of the PLTS were calculated by recording the press values of the observation points (Figure 6). A comparison of the hydraulic gradients, calculated using semiempirical formulas, loop test, and (8), is

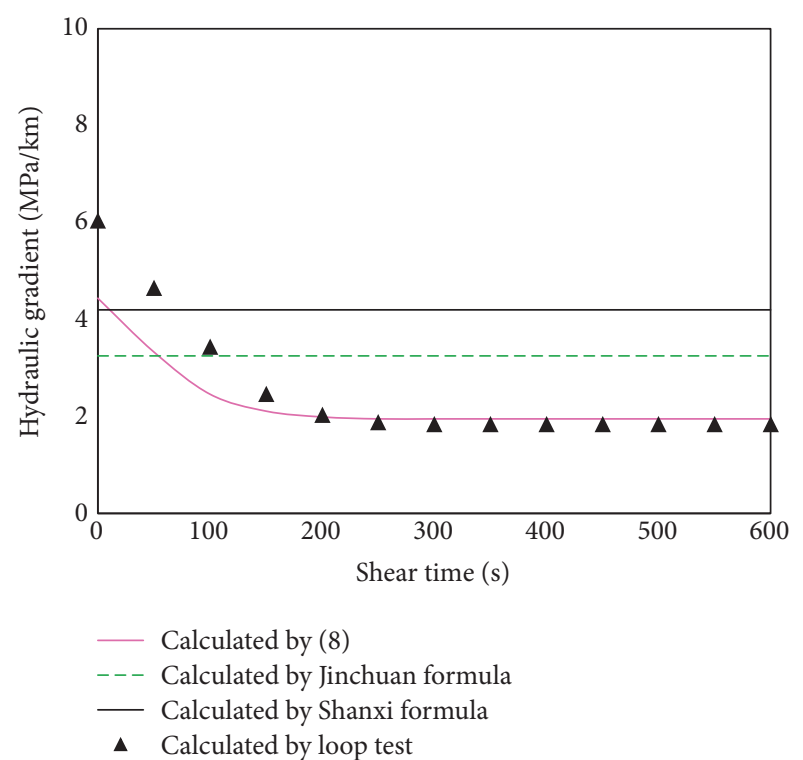

FIgURE 7: Comparison of calculated hydraulic gradient using different methods.

shown in Figure 7. Comparing with the balance hydraulic gradient obtained in the semi-industrial loop test, the computational errors of those calculated by using the time-varying hydraulic gradient model, Jinchuan formula, and Shanxi formula are $15 \%, 78 \%$, and $130 \%$, respectively. Therefore, the time-varying hydraulic gradient model is more feasible and reliable than semiempirical formulas.

\section{Conclusions}

The conclusions are made as follows:

(i) FS of PLTS can not only be stretched or damaged by mechanical mixing, but also lapped and recombined through flocculant bridging. This dynamic damage and recovery process of the FS is the core of the flocculent structure theory. Laboratory shear tests have validated that PLTS is consistent with a shear-thinning pseudo-plastic fluid rather than a timeinvariant Bingham plastic fluid. Therefore, the time-varying hydraulic gradient model of PLTS based on the theory of flocculent structure and the Herschel-Bulkley model is more scientific and reasonable.

(ii) The shear-thinning characteristics of PLTS are determined by the FS growth level. The shear stress, apparent viscosity, and hydraulic gradient had the highest values when the FS were fully developed and then declined gradually and reached a dynamic balance with the damaging process of FS. Accordingly, additional mechanical agitation of the PLTS before transportation can completely destroy the FS and reduce the hydraulic gradient effectively.

(iii) In the case of paste-like tailings in long-distance pipeline transportation, the time-varying hydraulic gradient model, which produces smaller errors than frequently used semiempirical formulas, has proved to be a feasible and highprecision solution for hydraulic gradient calculation. 


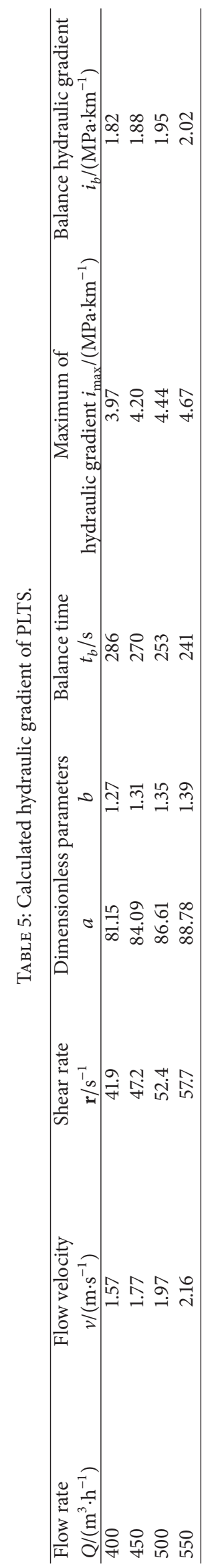




\section{Conflicts of Interest}

The authors declare that there are no conflicts of interest regarding the publication of this paper.

\section{Acknowledgments}

This study was supported by a grant from the National Key R\&D Program of China (2017YFC0804605).

\section{References}

[1] E. Yilmaz, A. Kesimal, B. Ercikdi, and R. Kaya, "The use of paste for disposal of mill tailings," in Proceedings of the $3 r d$ International Scientific Conference on Modern Management of Mine Producing, Geology and Environmental Protection, pp. 109-120, Varna, Bulgaria, 2003.

[2] R.-B.-M. Verburg, "Environmental benefits associated with the use of paste for surface disposal of tailings," in Proceedings of the 50th Canadian Geotechnical Conference of the Canadian Geotechnical Society, pp. 484-491, Ottawa, Canada, 1997.

[3] S. Li, Q. Chen, and X. Wang, "Superiority of filtered tailings storage facility to conventional tailings impoundment in southern rainy Regions of China," Sustainability (Switzerland), vol. 8, no. 11, article no. 1130, 2016.

[4] W. Yan, "Tailings disposal methods and applications at home and abroad," Metal Mine, vol. 483, no. 9, pp. 1-14, 2016 (Chinese).

[5] S. LI, X.-M. WANG, and Q.-L. ZHANG, "Dynamic experiments on flocculation and sedimentation of argillized ultrafine tailings using fly-ash-based magnetic coagulant," Transactions of Nonferrous Metals Society of China (English Edition), vol. 26, no. 7, pp. 1975-1984, 2016.

[6] S. Li and X.-M. Wang, "Fly-ash-based magnetic coagulant for rapid sedimentation of electronegative slimes and ultrafine tailings," Powder Technology, vol. 303, pp. 20-26, 2016.

[7] X.-M. Wang, J.-W. Zhao, J.-H. Xue, and G.-F. Yu, "Features of pipe transportation of paste-like backfilling in deep mine," Journal of Central South University of Technology (English Edition), vol. 18, no. 5, pp. 1413-1417, 2011.

[8] A. Haimoni and D. J. Hannant, "Hydraulic transport of solids in pipes: a simple method for the prediction of pressure drop," Materials and Structures, vol. 26, no. 3, pp. 144-151, 1993.

[9] E.-U. Pornillos, "A technique for measuring the reduction of yield stress of thickened tailings," in Proceedings of the 14th International Seminar on Paste and Thickened Tailings, pp. 167173, Australian Centre of Geomechanics, Perth, Australia, 2011.

[10] P. K. Senapati and B. K. Mishra, "Design considerations for hydraulic backfilling with coal combustion products (CCPs) at high solids concentrations," Powder Technology, vol. 229, pp. 119-125, 2012.

[11] S. Li, X.-M. Wang, Q.-L. Zhang, and S. Wang, “Time-varying behavior of paste-like super-fine tailings in long self-flowing transportation," Journal of Northeastern University (Natural Science), vol. 37, no. 7, pp. 1045-1049, 2016 (Chinese).

[12] R.-J. Jewell and A.-B. Fourie, Paste and Thickened Tailings: A Guide, Australian Centre for Geomechanics, Perth, Australia, 2nd edition, 2006.

[13] F. Palkovits, "Paste thickening: considerations for backfill vs. tailings management," Engineering and Mining Journal, vol. 212, no. 9, pp. 34-40, 2011.
[14] H. E. Ries Jr. and B. L. Meyers, "Flocculation mechanism: Charge neutralization and bridging," Science, vol. 160, no. 3835, pp. 1449-1450, 1968.

[15] E. Antunes, F. A. P. Garcia, P. Ferreira, A. Blanco, C. Negro, and M. G. Rasteiro, "Modelling PCC flocculation by bridging mechanism using population balances: Effect of polymer characteristics on flocculation," Chemical Engineering Science, vol. 65 , no. 12 , pp. 3798-3807, 2010.

[16] E. A. Toorman, "Modelling the thixotropic behaviour of dense cohesive sediment suspensions," Rheologica Acta, vol. 36, no. 1, pp. 56-65, 1997.

[17] R.-P. Chhabra and J.-F. Richardson, Non-Newtonian Flow and Applied Rheology: Engineering Applications, ButterworthHeinemann, Oxford, UK, 2008.

[18] Q.-L. Zhang, G.-Y. Hu, and X.-M. Wang, "Hydraulic calculation of gravity transportation pipeline system for backfill slurry," Journal of Central South University of Technology, vol. 15, no. 5, pp. 645-649, 2008.

[19] I.-T. Seitshiro, J. Katende, and H. Sato, "Slurry pipeline design of multi-sized solids: application of innovated models," International Journal of the Society of Materials Engineering for Resources, vol. 20, no. 2, pp. 201-206, 2014. 

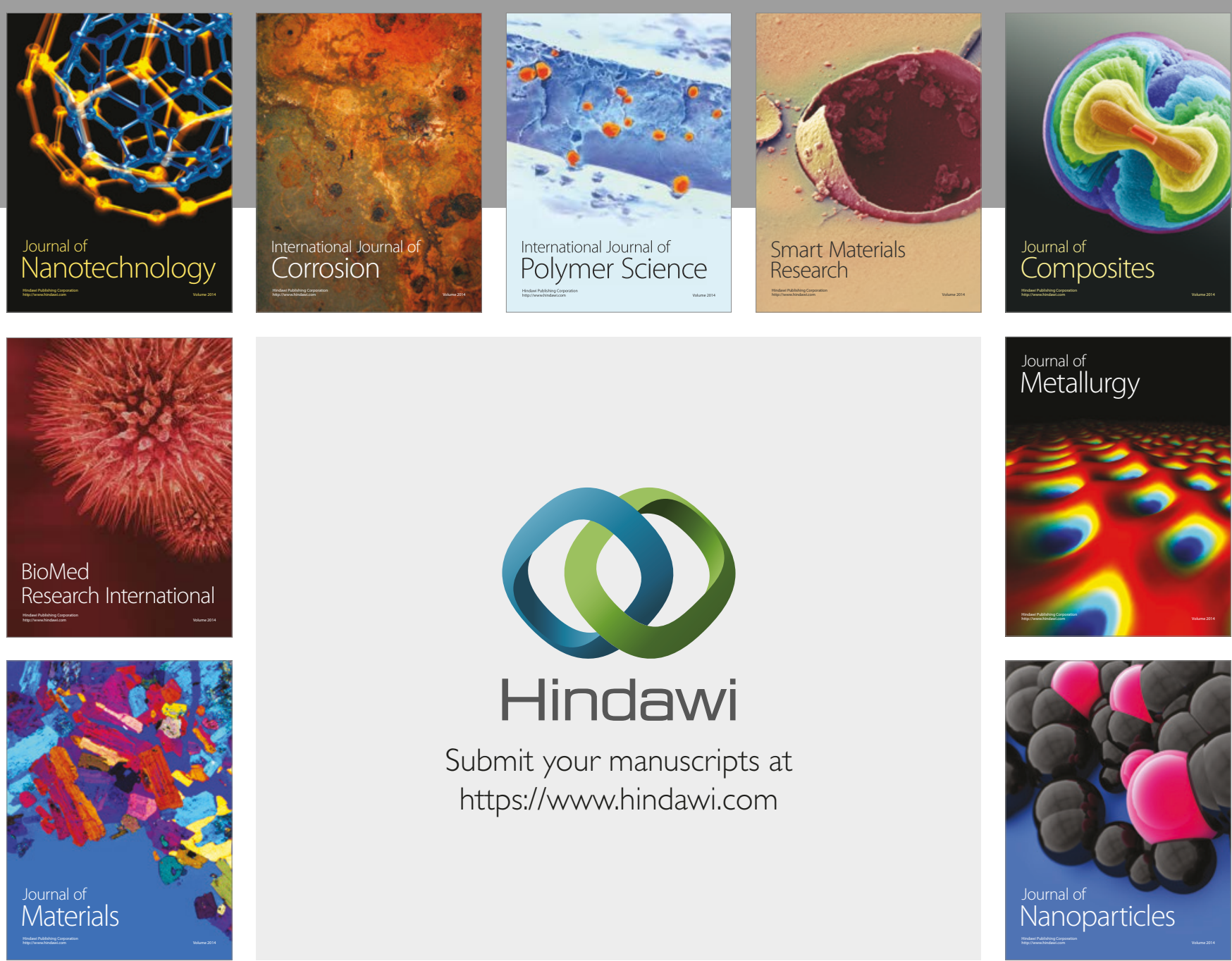

\section{Hindawi}

Submit your manuscripts at

https://www.hindawi.com
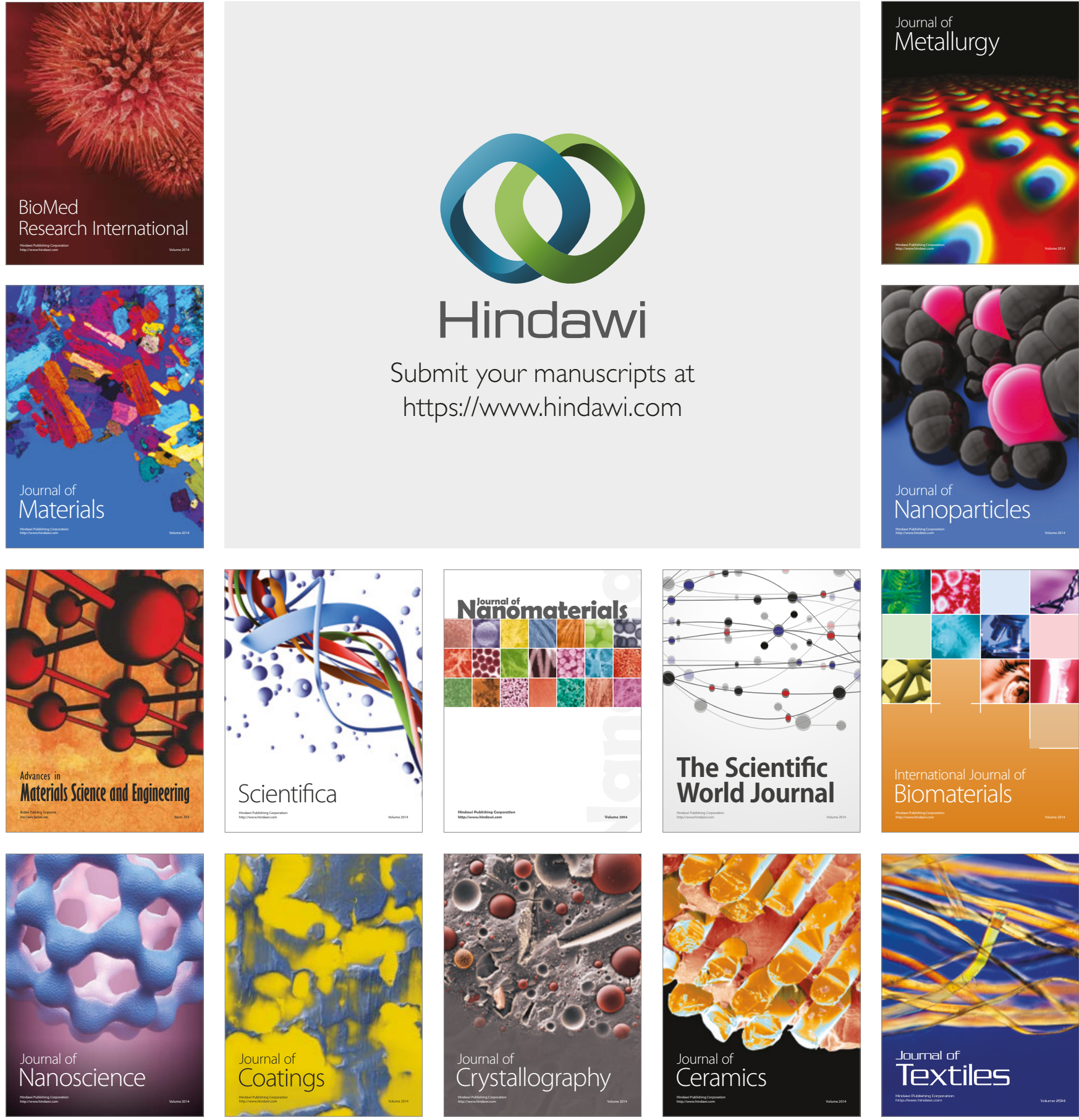

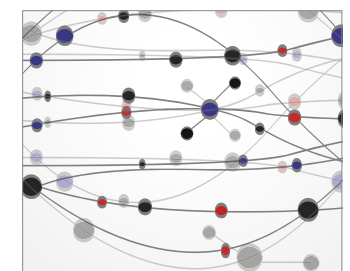

The Scientific World Journal
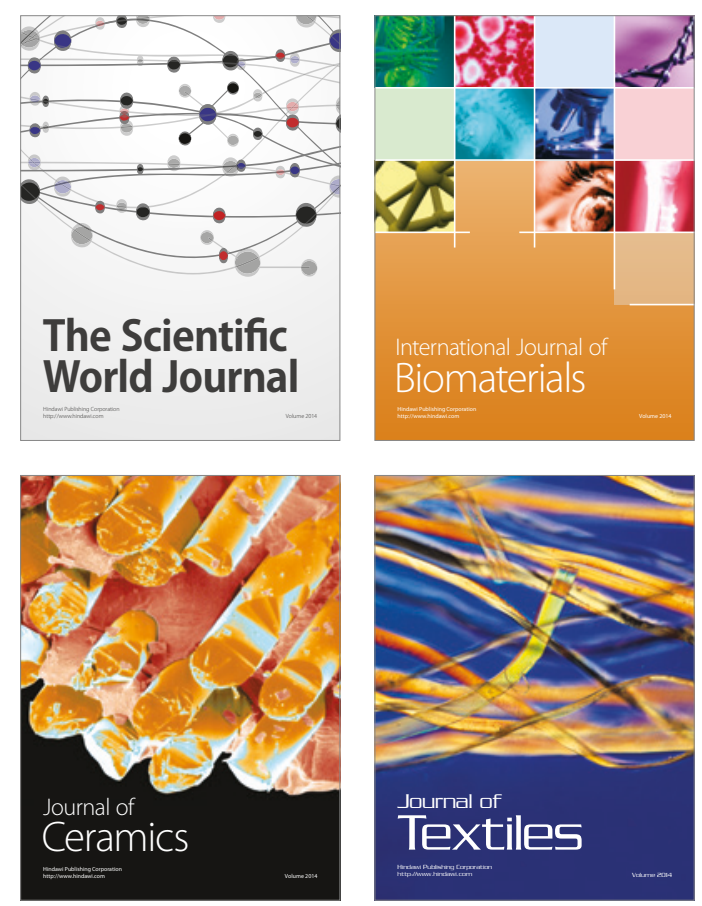